IJ§ER

ISSN: 2149-5939
International Journal of Social Sciences and Education Research

Online, http://dergipark.gov.tr/ijsser

Volume: 3(2), 2017

\title{
Dış ticaret ve ekonomik büyüme arasındaki nedensellik ilişkisi: Türkiye örneği
}
The causality relationship between foreign trade and economic growth: The case of Turkey

\author{
Bedriye Tunçsiper ${ }^{1}$
}

\author{
Ezgi Zeynep Rençber²
}

Accepted Date: 14 / 02 / 2017

\section{$\ddot{O} z$}

Received Date: $01 / 09$ / 2016

Dış ticaret kavramı malların ve sermayenin ülke sınırlarının dışına akışıyla ilgili bir kavram olup, ülkenin reel gelirinde yıldan yıla meydana gelen artışlardan ibaret olan ekonomik büyüme olgusu ile yakından ilgilidir. Yıllara ve ülkelerin yapısal özelliğine göre bu iki değişken arasındaki ilişkinin yönü ve önemi de değişiklik göstermektedir. Bu çerçevede bu çalı̧̧manın amacı Türkiye ekonomisinde diş ticaret ve ekonomik büyüme arasındaki nedensellik ilişkisinin varlı̆̆ının incelenmesidir. Bu sebeple 2002:01-2016:02 dönemine ait üçer aylık ihracat, ithalat ve GSYH verileri kullanılarak analiz gerçekleştirilmiştir. Yapılan Granger nedensellik analizi sonucuna göre 2002:012016:02 döneminde Türkiye 'de ithalattan ekonomik büyümeye doğru tek yönlü nedensellik ilişkisi saptanmıştır. Ayrıca ithalattan da ihracata doğru tek yönlü nedensellik ilişkisi tespit edilmiştir. Bu durum Türkiye ekonomisi için "ithalat İtişli Büyüme "ve "İthalata Dayalı İhracat" hipotezlerinin geçerli olduğunu kanttlar niteliktedir.

Anahtar sözcükler: Ithalat İhracat, Ekonomik Büyüme, Granger Nedensellik Analizi

\begin{abstract}
The concept of foreign trade is related with the flow of goods and capital out of the country. As well, it is in a close relation with economic growth which is just annual increase in country's real income. The importance and the causal relationship between these two variables change according to years and country's structure. Within this framework, this study aims to clarify the causality between foreign trade and economic growth for Turkish economy. Quarterly export, import and GDP data for 2002:01-2016:02 period is used for the analysis. Granger causality analysis result shows that one-sided causality from imports to economic growth exists for the period in Turkey. Besides, there is one-sided causality from imports to exports. These results prove "import-push growth" and "import-based export" hypotheses for Turkish economy.
\end{abstract}

Keywords: Import, export, economic growth, Granger Causality Analysis

\section{Giriș}

Ekonomik büyüme bir ülkenin üretim kapasitesinde yıldan yıla meydana gelen artışları ifade etmektedir. Ülkede gerçekleşen ekonomik büyümenin nüfus artış oranından daha yüksek oranda gerçekleşmesi kişi başına düşen geliri arttıracaktır ki bu da toplumun refah seviyesinde artışları beraberinde getirecektir. Ülkenin mal ve hizmet üretim kapasitesini dolayısıyla da toplumun refah seviyesini arttırmanın temel yolu ise kapasite kullanım oranlarının arttırılmasından geçmektedir. Ancak her ülkenin üretebileceği mal ve hizmetlerin belirli bir sınırı bulunmaktadır. Özellikle ge-

\footnotetext{
${ }^{1}$ Prof. Dr., Balıkesir Üniversitesi, Balıkesir, Türkiye, tbedriye@ balikesir.edu.tr

${ }^{2}$ Balıkesir Üniversitesi, Balıkesir, Türkiye, zeynep--23@hotmail.com
} 
Tunçsiper,B., Rençber, E.Z. (2017). Dış ticaret ve ekonomik büyüme arasındaki nedensellik ilişkisi: Türkiye örneği International Journal of Social Sciences and Education Research, 3(2), 619-630.

lişmekte olan ülkeler hızlı bir biçimde sanayileşmeyle yüksek büyüme trendini yakalamak istemektedirler. Ancak kapasiteyi arttırmada kullanılacak ulusal tasarruflar yetersiz kaldığından ülkeler için dış kaynak kullanımı gündeme gelmektedir.

Küreselleşmenin hat safhalara ulaştığı günümüzde ülkelerin uluslararası ticaret yapmadan ya da dış yardım almadan faaliyetlerini sürdürmesi oldukça zordur. Uluslararası ekonomik toplumların en belirgin özelliği de ülkelerin karşılıklı olarak birbirine bağımlılı̆̆ıdır. Aslında karşılıklı bağımlılık, ülkeler arasındaki mal ve hizmet ticaretinin bir sonucudur. Ülkeler arasında bu ekonomik ilişkilerin belirleyicisi ise dış ticareti oluşturan iki kavram olan ithalat ve ihracattır. Ülkelerin dış ekonomik faaliyetlerini sürdürebilmesi ve ülkenin ihtiyaç duyduğu ithalatı gerçekleştirebilmesi için ihracat gibi döviz kazandırıcı alanlara öncelik vermesi gerekir. Ancak özellikle gelişmekte olan ülkeler sermaye yetersizliği sebebiyle ülkenin gereksinim duyduğu ithalatı gerçekleştirmekte güçlük çekmekte bu da ekonomik büyüme ve kalkınmalarının önünde büyük engel teşkil etmektedir.

İthalat, ihracat ve ekonomik büyüme arasındaki nedensellik ilişkisinin yönü iktisatçılar tarafindan yıllardır tartışılan bir konu haline gelmiştir. Ancak bu üç değişken arasındaki ilişkinin yönü hakkında tam bir fikir birliğine varılamamıştır. Ele alınan döneme, ülkelerin yapısal özelliklerine ve izlenen yönteme göre değişkenler arasındaki ilişkinin yönü ve boyutu da değişmektedir. Öyle ki aynı ülke için yapılan çalışmalardan bile farklı sonuçlara varıldığı gözlemlenmiştir. Ancak ülkelerde uygulanacak büyüme ve kalkınma politikalarının doğru bir biçim de saptanması açısından dış ticaret ve ekonomik büyüme arasındaki ilişkinin yönü ve boyutunun tespit edilmesi büyük önem taşımaktadır. Dış ticaretin yalnızca ihracat boyutunun ele alınarak ülkelerde dış ticaret ve ekonomik büyüme etkileşiminin saptanmaya çalışılması gerçekten uzak ve çelişkili sonuçlar elde edilmesine neden olmaktadır. Bu sebeple ithalatın analize dahil edilmesi ulaşılacak sonuçlara göre daha uygun politikaların oluşturulmasına imkan sağlayacaktır.

Dış ticaret ve ekonomik büyüme arasındaki nedensellik ilişkisi tespit edilirken karşılaşılabilecek muhtemel hipotezler şu şekildedir:

İlk durum ihracattan ekonomik büyüme doğru tek yönlü nedensellik ilişkisinin saptandığı durumdur. Bu durum kısaca ihracat çekişli büyüme hipotezi olarak adlandırılır. İhracat çekişli büyüme hipotezinde ülkenin ihracat kapasitesinde meydana gelen artışlar kaynakların etkin olmayan alanlardan etkin alanlara yönlendirilmesini sağlayacaktır. Kaynakların etkin alanlarda kullanılmaya başlamasıyla üretimde verimlilik artacak ve bu durum ekonomik büyümeye pozitif yönde katkı sağlayacaktır.

Ayrıca ihracat artışı sayesinde kazanılan döviz ülkenin üretimde gereksinim duyduğu sermaye ve ara malı ithalatı için finansman kaynağını oluşturacak, bu durum ülkenin üretim kapasitesine olumlu yönde etki yaparak büyümeyi tetikleyecektir. İhracat artışı pazarı küçük ya da iç talep yetersizliği yaşayan ülkeler için pazarın genişlemesine katkıda bulunacaktır. Pazarın genişlemesiyle atıl kapasiteler kullanılmaya başlanacak ve birim maliyetler azalacaktır. Ayrıca ihracat artış1 rekabet kanalını etkin hale getireceğinden üretimde daha ileri düzeyde teknolojiler kullanılacak böylece üretilen mal ve hizmetlerin kalitesi yükselecektir.

İkincisi ise ekonomik büyümeden ihracata doğru tek yönlü nedensellik ilişkisinin tespit edildiği durumdur. Bu durum büyüme çekişli ihracat hipotezine işaret etmektedir. Ekonomik büyümeyle birlikte artan gelire paralel olarak yapılan yeni yatırımlar ve sağlanan teknolojik ilerlemeler sayesinde ülkenin uluslararası piyasalarda rekabet gücü yükselmekte bu durum ihracata pozitif 
Tunçsiper,B., Rençber, E.Z.(2017). The causality relationship between foreign trade and economic growth: The case of Turkey.International Journal of Social Sciences and Education Research, 3(2), 619-630.

katkı sağlamaktadır. Teknolojik ilerlemeler verimlilik artışını berberinde getirdiğinden birim başına maliyetler azalmaktadır. Ekonomik büyümenin yarattığı verimlilik artışı ülkede ihracata yönelik sektörlerde gerçekleştiği takdirde ihracat bu durumdan pozitif yönde etkilenecek ve artacaktır

Üçüncü durum ihracat ve ekonomik büyüme arasında çift yönlü nedensellik ilişkisinin bulunduğu durumdur. Bu durumda ekonomik büyümeden ihracata ve ihracattan ekonomik büyümeye doğru nedensellik ilişkileri birlikte görülür. İhracatta meydana gelen artış ekonomik büyümeyi teşvik etmekte ve büyümeyle birlikte artan gelir ticaretin yükselmesine katkıda bulunmaktadır.

Dördüncü durum ithalattan ekonomik büyümeye doğru tek yönlü nedensellik ilişkisinin bulunduğu durumdur. İthalat itişli büyüme olarak adlandırılan bu hipotezde ithalat, üretim için gerekli olduğu halde ülkede bulunmayan ya da bulunmasına rağmen nitelik bakımından eksik olan, ara ve sermaye malları ile teknolojik gelişmenin ülkeye ulaşmasında en önemli araçlardan biri olduğundan ekonomik büyümeye katkı sağlamaktadır.

Beşinci durum ekonomik büyümeden ithalata doğru tek yönlü nedensellik ilişkisinin bulunduğu durumdur. Büyüme çekişli ithalat hipotezi olarak adlandırılan bu durumda ekonomik büyümeye paralel olarak ülkenin üretim kapasitesinin yükselmesi ve buna bağlı olarak girdi ihtiyacının artmasıyla daha fazla sermaye ve ara malı ithal edilmekte dolayısıyla da ithalat yükselişe geçmektedir.

Altıncı durum büyümeden ithalata ve ithalattan büyümeye doğru çift yönlü nedensellik ilişkisinin bulunduğu durumdur. İthalat itişli büyüme ve büyüme çekişli ithalat hipotezlerinin birlikte görüldüğü bu durumda artan ithalat geliri ve büyümeyi yükseltmekte artan gelir ise tekrar ithalat artı̧̧ına sebebiyet vermektedir.

İthalat, ihracat ve ekonomik büyüme ilişkisi hakkında birçok çalışma yapılmasına rağmen teoride bu hipotezlerden hangisinin geçerli olduğu konusunda bir görüş birliğine varılamamış olması bu çalışmanın özünü oluşturmaktadır. Ayrıca elde edilecek sonuçlara göre oluşan bu hipotezler karşısında izlenecek politikalar da birbirinden farklı olmaktadır. Bütün bu koşullar birlikte değerlendirildiğinde bu çalışmanın amacı Türkiye ekonomisinde 2002:01-2016:02 döneminde çeyrek aylık ithalat, ihracat ve ekonomik büyüme verileri kullanılarak dış ticaret ve ekonomik büyüme arasındaki nedensellik ilişkisinin varlığının ve yönünün tespit edilmesidir.

\section{Literatür taraması}

İktisat yazınında ithalat ve ihracatın ekonomik büyüme üzerine yapmış olduğu etkiye yönelik tartışmalar Adam Smith ve David Ricardo' ya kadar dayanmaktadır. Klasik iktisatçılar dış ticaretin ülke refahını arttırdığına yönelik görüşleri savunmuşlardır. 1980'li yıllardan sonra ön plana çıkan içsel büyüme teorileri ise diş ticaretin dinamik etkilerine vurgu yaparak toplam faktör verimliliği ve bilgi birikimine paralel olarak ekonomik büyümeyi açıklamışlardır. Öte yandan PostKeynesyen yaklaşımlar ise ekonominin talep yönüne dikkat çekerek ekonomik büyüme ve dış ticaret ilişkilerinin açıklanmasında iç tasarruf oranları ile bütçe kısıtlarının yanında ödemeler bilançosu sınırlandırmalarına vurgu yapmaktadırlar. Bütün bu tartışmalara rağmen hala dış ticaret ve ekonomik büyüme ilişkisi hakkında kesin bir fikir birliğine varıldığını söylemek mümkün değildir. 
Tunçsiper,B., Rençber, E.Z. (2017). Dış ticaret ve ekonomik büyüme arasındaki nedensellik ilişkisi: Türkiye örneği International Journal of Social Sciences and Education Research, 3(2), 619-630.

Kravis (1970), 1835-1966 yıllarına ait ihracat ve büyüme verilerini kullanılarak 55 ülke için ihracat ve ekonomik büyüme ilişkisini değerlendirmiştir. Yapılan bu çalışma sonucunda ihracata dayalı büyüme hipotezini destekleyecek bulgulara ulaşılmıştır.

Heller ve Porter (1978), 1950-1973 dönemine ait verileri kullanarak 41 ülke için ihracat ve ekonomik büyüme ilişkisini araştırmışlardır. Çalışmadan elde edilen sonuca göre dış ticaret, ekonomik büyüme üzerine pozitif etki yapmaktadır. Ancak bu etki gelişmiş ülkelerde daha fazla hissedilmektedir.

Ram (1985), 1960-1977 dönemine ait ihracat ve büyüme verilerini kullanarak 73 ülkede ekonomik büyüme ve ihracat ilişkisini değerlendirmiştir. Çalışma sonucunda ihracata dayalı büyüme hipotezinin geçerliliği kabul edilmiştir.

Alavinasab (2013), İran için yapmış olduğu çalışmasında 1996-2011 dönemine ait yıllık verileri kullanmıştır. Johansen eşbütünleşme testi ve regresyon analizinin kullanıldığ cunda ithalatın büyümeyi negatif, ihracatın büyümeyi pozitif yönde etkilediği sonucuna ulaşmıştır.

Türkiye' de dış ticaret ve ekonomik büyüme üzerine yapılan çalışmaların literatür özeti ise aşağıda özetlenmiştir.

Köse ve Yiğidim (1997), yılında yaptıkları çalışmalarında 1980-1996 yılına ait çeyrek aylık verileri kullanarak ihracat, ithalat ve iktisadi büyüme arasındaki ilişkiyi araştırmışlardır. Granger nedensellik analizinin kullanıldığı bu çalışmanın sonucunda Türkiye'de iktisadi büyümeyi en fazla etkileyen değişkenin ithalat olduğu bulgusuna ulaşmışlardır.

Tuncer (2002), 1980-2000 dönemini kapsayan çalışmasında ihracat, ithalat, GSYH ve yat1rımlar arasındaki ilişkiyi üçer aylık verileri kullanarak araştırmıştır. Toda-Yamamoto nedensellik analizinin kullanıldığı bu çalışmada GSYH 'den ihracat doğru tek yönlü, yatırımlar ve ihracat arasında iki yönlü, GSYH ve ithalat arasında iki yönlü nedensellik ilişkisi saptanmıştır.

Erdoğan (2006), iktisadi büyüme ve ihracat arasındaki nedensellik ilişkisini araştırdığı çalışmasında 1923-2004 yıllarına ait ihracat, ithalat ve GSMH verilerini kullanmıştır. İhracat ve iktisadi büyüme arasında uzun dönemli ilişkinin saptandığı çalışmada ayrıca ihracat ve iktisadi büyüme arasında iki yönde nedensellik bulgusuna rastlanmıştır.

Gerni, Emsen ve Değer (2008), yaptıkları çalışmalarında 1980-2006 yıllarına ait verileri kullanarak ihracat ve ekonomik büyüme arasındaki ilişkiyi araştırmışlardır. Bu çalışma sonucunda ihracatın ekonomik büyüme üzerinde pozitif etkisinin olduğu ancak modele ithalatın dahil edilmesiyle ihracatın istatistiki açıdan anlamlılığını yitirdiği gözlemlenmiştir.

Kurt ve Berber (2008), 1989-2000 döneminde dışa açıklık ve ekonomik büyüme ilişkisini araştırdıkları çalışmalarında çeyrek aylık verileri kullanılarak VAR analizi gerçekleştirmişlerdir. Değişken olarak ithalatın GSMH' ye oranı ve ihracatın kullanıldığı bu çalışmada ekonomik büyüme ve ithalat arasında çift yönlü nedensellik ilişkisi, ihracattan ekonomik büyüme doğru tek yönlü nedensellik ilişkisi ve ithalattan ihracata doğru tek yönlü nedensellik ilişkisi saptanmıştır.

Aktaş (2009), 1996-2006 dönemine ait ihracat, ithalat ve ekonomik büyüme verilerini kullanarak Johansen eşbütünleşme analizine başvurduğu çalışmasında üç değişken arasında uzun dönemli ilişki olduğu bulgusuna ulaşmıştır. Ayrıca Granger nedensellik analizi sonucunda ithalat, ihracat ve ekonomik büyüme arasında çift yönlü nedensellik ilişkisinin bulunduğu bu çalışmada 
Tunçsiper,B., Rençber, E.Z.(2017). The causality relationship between foreign trade and economic growth: The case of Turkey.International Journal of Social Sciences and Education Research, 3(2), 619-630.

hata düzeltme yöntemine göre uzun dönemde hem büyüme çekişli ihracat hem de büyüme çekişli ithalat hipotezlerinin geçerli olduğu sonucuna ulaşılmıştır.

Bilgin ve Şahbaz (2009), çalışmalarında 1987-2007 dönemine ait aylık sanayi üretim endeksi ve ihracat verilerini kullanarak ihracat ve ekonomik büyüme arasındaki ilişkiyi araştırmışlardır. Değişkenler arasındaki uzun dönemli ilişkinin saptanması için Johansen eşbütünleşme testinin ve Toda-Yamamoto nedensellik testinin kullanıldığı çalışmanın sonucunda ihracata dayalı büyüme hipotezini destekleyen bulgulara ulaşılmıştır.

Taştan (2010), Türkiye' de ithalat, ihracat ve ekonomik büyüme arasındaki nedensellik ilişkisini araştırdığ çalışmasında 1985-2009 dönemine ait çeyrek aylık verileri baz alarak frekans alanı yöntemini kullanmıştır. Çalışmanın sonucunda ithalat itişli büyüme ve büyüme çekişli ihracat hipotezlerinin geçerli olduğu yönünde bulgular elde edilmiştir.

Gül ve Kamacı (2012), dış ticaret ve ekonomik büyüme ilişkisini gelişmiş ülkeler için 19802010, gelişmekte olan ülkeler için 1993-2010 dönemleri için panel veri analizi ile test etmişlerdir. Yapılan analiz sonucunda gerek gelişmiş ülkelerde gerekse gelişmekte olan ülkelerde ihracat ve ithalattan ekonomik büyüme doğru tek yönlü nedensellik ilişkisi saptanmıştır.

Saraç (2013), 1989-2011 dönemine ait çeyrek aylık verileri kullanarak ihracat, ithalat ve ekonomik büyüme ilişkisini doğrusal olmayan ekonometrik yöntemle araştırmıştır. Çalışma sonucunda ihracat ve ithalatın ekonominin daralma ve genişleme dönemlerinde ekonomik büyümeye pozitif etki ettiği şeklindeki içsel büyüme teorilerinin ithalat ve ihracat ile görüşlerinin geçerli olduğu tespiti yapılmıştır.

Korkmaz (2014), ihracata dayalı büyüme hipotezinin geçerliliğine yönelik sonuçlar bulduğu çalışmasında 1998-2003 yılına ait çeyrek aylık ihracat ve GSYH verilerini kullanmıştır. Çalışma sonucunda ihracattan ekonomik büyüme doğru tek yönlü nedensellik ilişkisi saptanmıştır.

Koçak ve Uçan (2014), üçer aylık ithalat, ihracat ve ekonomik büyüme verilerini kullanarak 1990-2011 dönemini kapsayan bir çalışma gerçekleştirmişlerdir. Çalışmada Granger nedensellik analizi ve eşbütünleşme testi kullanılmıştır ve ele alınan dönemde ekonomik büyüme ve dış ticaret arasında uzun dönemli ilişkinin olduğuna yönelik bulgulara ulaşmışlardır.

Sağlam ve Egeli (2014), Türkiye' de ihracata dayalı büyüme hipotezinin geçerliliğini araştırdıkları çalışmalarında 1999-2013 yılına ait üçer aylık ihracat ve GSYH verilerini kullanmışlardır. Çalışma sonucunda kısa dönemde iki değişken arasında çift yönlü nedensellik ilişkisine rastlanırken uzun dönemde sadece ihracattan büyüme doğru tek yönlü nedensellik ilişkisine rastlanmıştır.

Korkmaz ve Aydın (2015), 2002-2014 dönemine ait çeyrek aylık ithalat birim değer endeksi, ihracat birim değer endeksi ve GSYH verilerini kullanarak yapmış oldukları VAR analizi sonucunda ithalat ve ekonomik büyüme arasında çift yönlü nedensellik ilişkisi saptamış ve ithalat çekişli büyüme ve büyüme çekişli ithalat hipotezlerinin geçerliliği kabul edilmiştir.

Acet, Erdoğan ve Köksal (2016), Türkiye' de ihracat, ithalat ve ekonomik büyüme arasındaki nedensellik ilişkisini 1998-2013 dönemine ait çeyrek aylık verileri kullanarak incelemişlerdir. Çalışmanın sonucunda hem ihracat hem de ithalattan ekonomik büyüme doğru tek yönlü nedensellik ilişkisi saptanmıştır. Ancak ihracatın büyüme üzerindeki etkisinin ithal girdilere dayandığı vurgusu yapılarak ithalatın büyüme üzerindeki etkisi ön plana çıkarılmıştır. 
Tunçsiper,B., Rençber, E.Z. (2017). Dış ticaret ve ekonomik büyüme arasındaki nedensellik ilişkisi: Türkiye örneği International Journal of Social Sciences and Education Research, 3(2), 619-630.

Şerefli (2016), Granger nedensellik analizini kullanarak Türkiye' de dış ticaretin ekonomik büyüme üzerine etkisini araştırdığ çalışmasında 1975-2014 dönemine ait yıllık verileri kullanmıştır. Çalışma sonucunda ihracat, ithalat ve büyüme değişkenleri arasında bir nedensellik ilişkisi saptanamamıştır.

\section{Veri seti}

Bu çalışmada Türkiye ekonomisi için 2002:01-2016:02 dönemine ait çeyrek aylık ithalat, ihracat ve GSYH veriler kullanılarak diş ticaret ve ekonomik büyüme arasındaki ilişki incelenmiştir.

LnGSYH: Harcamalar yöntemi ile (1998=100 sabit fiyatlar ile) reel GSYH,

LnX: İhracat1,

LnM: İthalatı temsil etmektedir.

Bu ilişkiyi tahmin etmede kullanılan veriler TCMB Elektronik Veri Dağıtım Sisteminden derlenerek oluşturulmuştur. Çalışmada kullanılan GSYH, İthalat ve ihracat verilerinin logaritması alınmıştır. Kullanılan üç veride de mevsimsel etkiler tespit edildiğinden veriler Eviews-9.0 paket programıla mevsimsel etkilerinden arındırılmıştır.

\section{Analiz sonuçları}

\section{Serilerin dură̆anlı̆̆ının tespit edilmesi}

Seriler arasındaki ilişkilerin doğru bir biçimde saptanabilmesi ve sahte regresyon probleminden kaçınılabilmesi maksadıyla serilerin durağanlığı birim kök testleri yardımıyla araştırılmıştır. İthalat, ihracat verileri ve GSYH verilerinin birim kök içerip içermediği Genişletilmiş Dickey Fuller (ADF) ve Phillips-Perron (PP) birim kök testlerinden yardım alınarak incelenmiştir. Birim kök testi sonuçları tablo 1 ve tablo 2' de görülmektedir.

Tablo 1. ADF Birim Kök Testi sonuçları

\begin{tabular}{|c|c|c|c|c|c|c|c|}
\hline \multicolumn{2}{|c|}{ Değişkenler } & & T İstatistiği & $\% 1$ & $\% 5$ & $\% 10$ & P Değeri \\
\hline \multirow{2}{*}{ LnGSYHsa } & Düzeyde & $\begin{array}{c}\text { Trendli } \\
\text { ve Sabit } \\
\text { Terim }\end{array}$ & -2.9377 & -4.1408 & -3.4969 & -3.1775 & 0.1595 \\
\hline & 1.Fark & $\begin{array}{l}\text { Sabit Te- } \\
\text { rim }\end{array}$ & -8.1532 & -3.5550 & -2.9155 & -2.5955 & $0.0000^{*}$ \\
\hline \multirow[t]{2}{*}{ LnXsa } & Düzeyde & $\begin{array}{c}\text { Trendli } \\
\text { ve Sabit } \\
\text { Terim } \\
\end{array}$ & -2.0139 & -4.1445 & -3.4986 & -3.1785 & 0.5801 \\
\hline & 1.fark & $\begin{array}{c}\text { Sabit Te- } \\
\text { rim }\end{array}$ & -6.5804 & -3.5626 & 2.9187 & 2.5972 & $0.0000^{*}$ \\
\hline \multirow[t]{2}{*}{$L n M s a$} & Düzeyde & $\begin{array}{c}\text { Trendli } \\
\text { ve Sabit } \\
\text { Terim }\end{array}$ & -2.3109 & -4.1305 & -3.4921 & -3.1748 & 0.4212 \\
\hline & 1.Fark & $\begin{array}{l}\text { Sabit Te- } \\
\text { rim }\end{array}$ & -4.5755 & -3.5526 & -2.9145 & -2.5950 & $0.0005^{*}$ \\
\hline
\end{tabular}


Tunçsiper,B., Rençber, E.Z.(2017). The causality relationship between foreign trade and economic growth: The case of Turkey.International Journal of Social Sciences and Education Research, 3(2), 619-630.

Tablo 2. PP Birim Kök Testi sonuçları

\begin{tabular}{|c|c|c|c|c|c|c|c|}
\hline \multicolumn{2}{|c|}{ Değișkenler } & & $\mathrm{T}$ İstatistiği & $\% 1$ & $\% 5$ & $\% 10$ & P Değeri \\
\hline \multirow[t]{2}{*}{$\operatorname{LnGSYHsa}$} & Düzeyde & $\begin{array}{c}\text { Trendli } \\
\text { ve Sabit } \\
\text { Terim }\end{array}$ & -3.0015 & -4.1273 & -3.4906 & -3.1739 & 0.0927 \\
\hline & 1.Fark & $\begin{array}{c}\text { Sabit Te- } \\
\text { rim }\end{array}$ & -7.9919 & -3.5526 & -2.9145 & -2.5950 & $0.0000 *$ \\
\hline \multirow[t]{2}{*}{$\operatorname{LnXsa}$} & Düzeyde & $\begin{array}{c}\text { Trendli } \\
\text { ve Sabit } \\
\text { Terim }\end{array}$ & -1.7889 & -4.1273 & -3.4906 & -3.1739 & 0.6971 \\
\hline & 1.fark & $\begin{array}{l}\text { Sabit Te- } \\
\text { rim }\end{array}$ & -6.5691 & -3.5526 & 2.9145 & 2.5950 & $0.0000 *$ \\
\hline \multirow[t]{2}{*}{ LnMsa } & Düzeyde & $\begin{array}{c}\text { Trendli } \\
\text { ve Sabit } \\
\text { Terim }\end{array}$ & -1.8717 & -4.1273 & -3.4906 & 3.1739 & 0.6560 \\
\hline & 1.Fark & $\begin{array}{c}\text { Sabit Te- } \\
\text { rim }\end{array}$ & -4.2681 & -3.5526 & -2.9145 & -2.5950 & $0.0012^{*}$ \\
\hline
\end{tabular}

Seriler çeyreklik olduğu için gecikme uzunluğu Akaike bilgi kriterine göre 4 olarak alınmıştır. Tablo 1' de ve tablo 2' de görüldüğü gibi ADF ve PP birim kök testlerine göre serilerin düzey değerleri için birim kökün bulunduğunu ifade eden $\mathrm{H}_{0}$ hipotezi reddedilmemiş ve serilerin durağan olmadığına karar verilmiştir. Serilerin 1. Farkı alındığında her iki serinin de t istatistik değeri, $\% 5$ kritik değerin üzerinde olduğu için $\mathrm{H}_{0}$ hipotezi reddedilmiş ve seriler durağan hale gelmiştir.

\section{Serilerin arasındaki nedenselliğin incelenmesi}

Çalışmada değişkenler arasındaki nedensellik ilişkisi ve bu ilişkinin yönü, "Granger Nedensellik Testi" kullanılarak incelenmiştir. Granger nedensellik testine kısa bir açıklama getirecek olursak eğer ithalat ya da ihracat ekonomik büyümenin Granger nedeni ise ithalat ve ihracatta meydana gelecek değişmeler ekonomik büyümeyi de etkileyecektir. Bu sebeple ekonomik büyüme başka değişkenlerle analiz edildiğinde regresyona ithalat ve ihracatın geçmiş veya gecikmeli değerleri eklendiğinde tahmin anlamlı yönde iyileşiyorsa ithalat ve ihracat ekonomik büyümenin Granger nedenidir diyebiliriz. (Gujarati, 2004: 697).

Bu ilişkiyi gösteren Nedensellik denklemimiz şu şekilde tahmin edilmiştir:

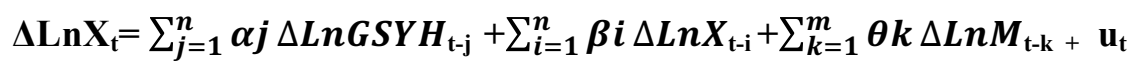

$$
\Delta \operatorname{LnGSYH} H_{\mathrm{t}}=\sum_{i=1}^{m} \vartheta i \Delta \operatorname{LnGSYH} H_{\mathrm{t}-\mathrm{j}}+\sum_{j=1}^{m} Y i \Delta \operatorname{LnX} X_{\mathrm{t}-\mathrm{j}}+\sum_{k=1}^{m} \phi k \Delta \operatorname{Ln} M_{\mathrm{t}-\mathrm{k}}+\mathrm{u}_{\mathrm{t}}
$$

$$
\Delta \operatorname{LnM}_{\mathrm{t}}=\sum_{i=1}^{m} \lambda i \Delta \operatorname{LnGSYH_{\mathrm {t}-\mathrm {j}}}+\sum_{j=1}^{m} P i \Delta \operatorname{Ln} X_{\mathrm{t}-\mathrm{j}}+\sum_{k=1}^{m} \delta k \Delta \operatorname{Ln} M_{\mathrm{t}-\mathrm{k}}+\mathrm{u}_{\mathrm{t}}
$$


Tunçsiper,B., Rençber, E.Z. (2017). Dış ticaret ve ekonomik büyüme arasındaki nedensellik ilişkisi: Türkiye örneği International Journal of Social Sciences and Education Research, 3(2), 619-630.

Tablo 3. Gecikme sonuçları

\begin{tabular}{|c|c|c|c|c|c|}
\hline Gecikme & LR & FPE & AIC & SC & HQ \\
\hline $\mathbf{0}$ & NA & $8.33 \mathrm{e}-09$ & -10.0898 & $-9.9783^{*}$ & -10.0469 \\
\hline $\mathbf{1}$ & 18.5888 & $8.01 \mathrm{e}-09$ & -10.1296 & -9.6835 & -9.9580 \\
\hline $\mathbf{2}$ & 32.9324 & $5.52 \mathrm{e}-09^{*}$ & -10.5059 & -9.7252 & $-10.2056^{*}$ \\
\hline $\mathbf{3}$ & 5.7081 & $6.85 \mathrm{e}-09$ & -10.2990 & -9.1838 & -9.8701 \\
\hline $\mathbf{4}$ & 22.4849 & $5.58 \mathrm{e}-09$ & $-10.5215^{*}$ & -9.0716 & -9.9663 \\
\hline
\end{tabular}

Tablo 3 gecikme sonuçlarını göstermektedir. İlgili Kriterler dikkate alındığında en uygun gecikme uzunluğunun 2 olduğu görülmektedir.

Tablo 4.Granger Nedensellik Analizi sonuçları

\begin{tabular}{|c|c|c|c|}
\hline & F İstatistik & Prob & Sonuç \\
\hline $\operatorname{Ln} G S Y H \rightarrow \operatorname{Ln} X$ & 1.104 & 0.339 & Nedensellik yok \\
\hline $\operatorname{LnX} \rightarrow \operatorname{LnGSYH}$ & 1.534 & 0.225 & Nedensellik yok \\
\hline $\operatorname{LnGSYH} \rightarrow \operatorname{Ln} M$ & 0.485 & 0.618 & Nedensellik yok \\
\hline $\operatorname{Ln} M \rightarrow \operatorname{LnGSYH}$ & 4.012 & 0.024 & Nedensellik var \\
\hline $\operatorname{Ln} X \rightarrow \operatorname{Ln} M$ & 0.070 & 0.932 & Nedensellik yok \\
\hline $\operatorname{Ln} M \rightarrow \operatorname{LnX}$ & 4.180 & 0.020 & Nedensellik var \\
\hline
\end{tabular}

Gecikme uzunluğunun iki olarak saptandığı durumda nedensellik analizi yapıldığında elde edilen sonuçlar tablo 4'te gösterilmiştir. Granger nedensellik analizi sonucuna göre Türkiye' de ilgili dönemde ithalattan ekonomik büyümeye ve ithalattan ihracata doğru tek yönlü nedensellik ilişkisi saptanmıştır. Buna karşılık büyümeden ihracata ve ithalata, ihracattan da büyümeye ve ithalata doğru bir nedensellik ilişkisi bulunamamıştır.

\section{Sonuç}

Bu çalışmada Türkiye ekonomisinde dış ticaret ve ekonomik büyüme arasındaki nedensellik ilişkisi araştırılmıştır. Bu kapsamda 2002: 01-2016: 02 dönemine ait çeyrek aylık ithalat, ihracat ve GSYH verileri kullanılmıştır. İlk olarak çalışmada kullanılan üç değişkeninde durağanlığı birim kök testleri yardımıyla sınanmıştır. Ele alınan üç değişkeninde düzey değerlerinde durağan olmadığı ancak birinci farkları alındığında durağan hale geldiği görülmüştür. Daha sonra ithalat, ihracat ve büyüme değişkenleri arasındaki nedensellik ilişkisinin saptanması için Granger nedensellik analizine başvurulmuştur.

Granger nedensellik analizi sonucuna göre Türkiye' de 2002: 01-2016: 02 döneminde ithalattan ekonomik büyümeye ve ithalattan ihracata doğru tek yönlü nedensellik ilişkisi saptanmıştır. Yani ithalat hem ekonomik büyümenin hem de ihracatın nedeni olarak bulunmuştur. Yapılan nedensellik analizine göre ihracat ve ekonomik büyüme arasında herhangi bir nedensellik ilişkisinin bulunmaması Türkiye'de ilgili dönemde ihracata dayalı büyüme hipotezinin geçerli olmadığını göstermektedir. 
Tunçsiper,B., Rençber, E.Z.(2017). The causality relationship between foreign trade and economic growth: The case of Turkey.International Journal of Social Sciences and Education Research, 3(2), 619-630.

Bu çalışmadan elde edilen sonuçlar Türkiye'de diş ticaret ve ekonomik büyüme ilişkisini inceleyen diğer çalışmalarla karşılaştıııldığında Yiğidim ve Köse (1997), Gerni, Emsen ve Değer (2008), gibi yazarların çalışmalarından elde ettikleri sonuçlarla aynıdır. Yine çalışmadan elde edilen sonuçlar çalışmalarında ithalattan büyümeye ve büyümeden ithalata doğru çift yönlü nedensellik ilişkisi sonucuna ulaşan Korkmaz ve Aydın'ın (2015), bulmuş olduğu sonuçla ve Kurt ve Berber (2008), Acet, Erdoğan ve Köksal (2016), gibi yazarların hem ithalattan ekonomik büyümeye hem de ihracattan ekonomik büyümeye doğru bulmuş oldukları tek yönlü nedensellik ilişkisi sonucuyla kısmen benzerlik göstermektedir.

Tüm bu sonuçlar Türkiye ekonomisinin gerçeğini yansıtmaktadır. Türkiye'de ihracat sektörleri ülkenin üretimde ihtiyacı olan hammadde ve ara mallarının finansmanını için gerekli dövizi sağlamaktadır. Buna karşılık yeni teknolojilerin geliştirilmesi ya da üretimde kullanılacak yeni metotların oluşturulması için yeterli olacak kadar araştırma ve geliştirme faaliyetlerinde bulunmamaktadır. Bu sebeple ihracatın ekonomik büyüme üzerindeki etkisi sınırlı kalmaktadır.

İthalat büyümenin ve ihracatın nedeni olarak bulunmuştur. Nitekim Türkiye'nin ihracatı gerçekleştirmiş olduğu ithalatına paralel olarak ilerlemektedir. İthalat ile birlikte ülkenin ihraç malları üretebilmek için ihtiyacı olduğu halde ülkede mevcut olmayan ara ve sermaye malları ülkeye giriş yapmaktadır. Bu sayede ülkenin toplam üretim kapasitesi artarak ekonomik büyümeyi arttırmaktadır. Tüm bu sonuçlar ilgili dönemde Türkiye' de “ İthalat İtişli Büyüme “ve “ İthalata Dayalı İhracat " hipotezlerinin geçerli olduğunu göstermektedir. Ancak bütün bu bulgular ithalata dayalı olarak büyümenin gerçekleştiği Türkiye'de dış açığın finansmanı sorununu da beraberinde getirecektir. Bu durumda yapılan ithalatın büyük ölçüde ihracat gelirleri ile gerçekleştirilmesi büyük önem ifade etmektedir.

\section{Kaynakça}

Acet, H., Erdoğan, S., ve Köksal, M. (2016). "İthalat, İhracat ve Büyüme Arasındaki Nedensellik İlişkisi: Türkiye Uygulaması “, Sosyal ve Ekonomik Araştırmalar Dergisi, 16(31), ss.145-161.

Aktaş, C. (2009). “Türkiye'nin İhracat, İthalat ve Ekonomik Büyüme Arasındaki Nedensellik Analizi “, Kocaeli Üniversitesi Sosyal Bilimler Enstitüsü Dergisi, 18(2), ss.35-474.

Alavinasab, S.M. (2013). 'Foreign Trade and Economic Growth in Iran: An Empirical Study", International Journal of Acedemic Research in Business and Social Sciences, 3(11) ss.508-519.

Bilgin, C. ve Şahbaz, A. (2009). “Türkiye'de Büyüme ve İhracat Arasındaki Nedensellik İlişkileri “, Gaziantep Üniversitesi Sosyal Bilimler Dergisi, (1)8, ss.177-198.

Erdoğan, M. (2006). “Türkiye'nin İhracat Yapısındaki Değişme ve Büyüme İlişkisi Kontegrasyon ve Nedensellik Testi uygulaması “, Selçuk Üniversitesi Karaman IIIBF Dergisi, 10(9), ss.30-39.

Gerni, C., Emsen ,O.S ve Değer, M.K. (2008). “İthalata Dayalı İhracat ve Ekonomik Büyüme: 1980-2006 Türkiye Deneyimi” 2. Ulusal İktisat Kongresi, İzmir

Gujarati, D.N. (2004), Basic Econometrics, New York: McGraw-Hill.

Gül, E. ve Kamac1, A. (2012). "Dış Ticaretin Büyüme Üzerine Etkileri: Bir Panel Veri Analizi “, Uluslararası Alanya İşletme Fakültesi Dergisi, 4(3), ss.81-91.

Heller, P. ve Porter, S. (1978). "Exports and Growth” Journal of Development Economics 5(1978), 1(3) ss. $150-165$.

Korkmaz, S. (2014). "Türkiye Ekonomisinde İhracat ve Ekonomik Büyüme Arasındaki Nedensellik İlişkisi “, Business and Economics Research Journal, 5(4), ss.119-128. 
Tunçsiper,B., Rençber, E.Z. (2017). Dış ticaret ve ekonomik büyüme arasındaki nedensellik ilişkisi: Türkiye örneği International Journal of Social Sciences and Education Research, 3(2), 619-630.

Korkmaz, S. ve Aydın, A. (2015). “Türkiye’de Dış Ticaret ve Ekonomik Büyüme İlişkisi: Nedensellik Analizi “, Eskişehir Osmangazi Üniversitesi İIBF Dergisi, 10(3), ss.47-76.

Kravis, I.B. (1970). ' Trade as a Handmaiden of Growth: Similarities Between The Nineteen Hand Twentieth Centuries " The Economic Journal, 80 (320), ss.850-872

Kurt, S. ve Berber, M. (2008). “Türkiye’de Dışa Açıklık ve Ekonomik Büyüme, İktisadi ve İdari Bilimler Fakültesi Dergisi “, 22(2), ss.57-80.

Ram, R. (1985). "Exportsand Economic Growth: Some Additional Evidence” Economic Development and Cultural Change, 33 (2), ss.415-425.

Sağlam, Y.ve Egeli, H.A. (2015). “İhracata Dayalı Büyüme Hipotezi Türkiye Örneği, Dokuz Eylül Üniversitesi Sosyal Bilimler Enstitüsü Dergisi “, 17(4), ss.517-530.

Saraç, T.B. (2013). “İhracat ve İthalatın Ekonomik Büyüme Üzerine Etkisi: Türkiye Örneği, Ege Akademik Bakış “, 13(2), ss.181-194.

Şerefli, M. (2016). "Dış Ticaretin Ekonomik Büyüme Üzerine Etkisi Türkiye Örneği“, Kastamonu Üniversitesi IIIBF dergisi, 13(5), ss.136-142.

Taştan, H. (2010). “Türkiye'de İhracat, İthalat ve Ekonomik Büyüme Arasındaki Nedensellik ilişkilerinin Spektral Analizi “,Ekonomi Bilimleri Dergisi, 2(1), ss.87-98.

Tuncer, İ. (2002). “Türkiye'de İhracat İthalat ve Büyüme: Toda-Yamamoto Yöntemiyle Granger Nedensellik Analizleri (1980- 2000)" Çukurova Üniversitesi, Sosyal Bilimler Enstitüsü Dergisi, 9 (9), ss.145160.

Türkiye Cumhuriyeti Merkez Bankası, (2016). TCMB Elektronik Veri Dağıtım Sistemi, 04.10.2016 tarihinde http://evds.tcmb.gov.tr/ adresinden erişildi.

Türkiye İstatistik Kurumu (2016). 27.10.2016 tarihinde http://www.tuik.gov.tr/Start.do adresinden erişildi.

Uçan, O ve Koçak, E. (2014). “Türkiye'de Dış Ticaret ve Büyüme Arasındaki İlişki “, Niğde Üniversitesi IIBF Dergisi, 7(2), ss.51-60.

Yiğidim, A. ve Köse N. (1997). "İhracat ve Ekonomik Büyüme Arasındaki İlişki, İthalatın Rolü Türkiye Örneği (1980-1996) “, Ekonomik Yaklaşım Dergisi, 8(26), ss.71-85. 
Tunçsiper,B., Rençber, E.Z.(2017). The causality relationship between foreign trade and economic growth: The case of Turkey.International Journal of Social Sciences and Education Research, 3(2), 619-630.

\section{Extended abstract in English}

Economic growth refers to the increases in the production of a countries capacity among years. The fact that the economic growth in the country is higher than the population increase will increase the income per capita, which will bring increases in the level of social welfare. The main way to increase the production capacity of the country's goods and services and therefore the welfare of the population is to increase the capacity utilization rates. However, there is a certain limit to the goods and services that each country can produce. Developing countries in particular want to quickly catch up with high growth trends in industrialization. However, because of the insufficient national savings to be used to increase capacity, outsourcing for countries is on the agenda.

Today, when globalization reaches the line, it is very difficult for countries to continue their activities without doing international trade or receiving foreign aid. The most prominent feature of international economic societies is the mutual interdependence of countries. In fact, interdependence is a result of trade of goods and services between countries. The determinants of these economic relations among countries are import and export, two concepts that constitute foreign trade. Priority should be given to foreign exchange earning areas such as exports so that countries can carry on their foreign economic activities and carry out the imports they need. However, especially developing countries have difficulty in realizing the importation required by the country due to capital deficiency, which constitutes a major obstacle to economic growth and development.

The direction of the causality relationship between imports, exports and economic growth has become a topic of debate for many years by economists. However, there was no consensus on the direction of the relationship between these three variables. The direction and magnitude of the relationship between the turnaround taken, the structural characteristics of the countries and the variables followed are also changing. It has been observed that even for the same country different results have been reached. However, determining the direction and dimension of the relationship between foreign trade and economic growth is crucial in determining the correct policies of growth and development to be implemented in countries. Trying to determine the interaction between foreign trade and economic growth in the countries by taking only the export dimension of foreign trade causes the real and distant results to be obtained. For this reason, the inclusion of imports in the analysis will allow for the creation of more favorable policies than the results to be achieved.

When the relation between foreign trade and economic growth is determined, there are probable hypotheses that can be obtained from the relationship between these two variables. The reason for these hypotheses is the export-driven growth hypothesis. According to this hypothesis, as the increase in the export of the country increases the need for resource utilization, with the increase of exports, the resources will start to be used in the more efficient areas, so the productivity of the country will increase and the economic growth will increase.

The second possible hypothesis that can be encountered is the growth-driven export hypothesis. At the core of the growth-driven exports hypothesis is the expectation that new investments made with increased income will increase the competitiveness of the country in foreign markets and that economic growth will have a positive impact on exports. 
Tunçsiper,B., Rençber, E.Z. (2017). Dış ticaret ve ekonomik büyüme arasındaki nedensellik ilişkisi: Türkiye örneği International Journal of Social Sciences and Education Research, 3(2), 619-630.

The third hypothesis is the import growth hypothesis. This hypothesis contributes to economic growth because imports are not in the country where they are needed for production, or are lacking in quality despite their presence, and intermediate and capital goods and technological development are among the most important means of reaching the country.

The fourth hypothesis is a growth-driven import hypothesis. In line with the economic growth in this hypothesis, as the production capacity of the country rises and accordingly the demand for inputs increases, more capital and intermediate goods are imported and therefore imports are increasing.

In addition to these four basic hypotheses, import-driven growth and growth-driven import hypotheses may appear together, as well as export-driven growth and growth-driven export hypotheses.

When all the conditions are evaluated together, the causality relation between foreign trade and economic growth in the Turkish economy is investigated in this study. Within this scope, quarterly import, export and GDP data for 2002: 01-2016: 02 period were used. First, the stability of the three variables used in the study was tested with the aid of unit root tests. In the three variables considered, it is seen that the level values are not static but become stable when the first differences are received. Then, the Granger causality analysis was applied to determine the causality relation between the variables of import, export and growth.

According to the results of Granger causality analysis, in the period of 2002: 01-2016: 02 in Turkey, one - way causality relation to import growth was found. In other words, imports are found both as economic growth and as the cause of export. According to the analyzed causality analysis, the absence of any causal relationship between exports and economic growth suggests that the export-based growth hypothesis is not valid in the relevant period in Turkey.

The results obtained without working reflect the reality of the Turkish economy. In Turkey, export sectors provide the necessary currency for the financing of raw materials and intermediate goods that the country needs in production. On the contrary, it does not have enough research and development activities to develop new technologies or to create new methods to be used in production. For this reason, the effect of exports on economic growth is limited. Import growth and found as the reason for export. As a matter of fact, it is progressing parallel to the imports that Turkey has exported. With imports, intermediary and capital goods that are not available in the country are entered into the country in order to be able to produce export goods of the country. In this way, the total production capacity of the country increases and it increases the economic growth. All these results show that the hypothesis "Imports Growth" and "Imports Based Export" are valid in Turkey in the related period. However, all these findings will bring about the problem of financing the foreign debts in Turkey where the growth is based on imports. In this case, it is very important to realize the imports with large export revenues. 